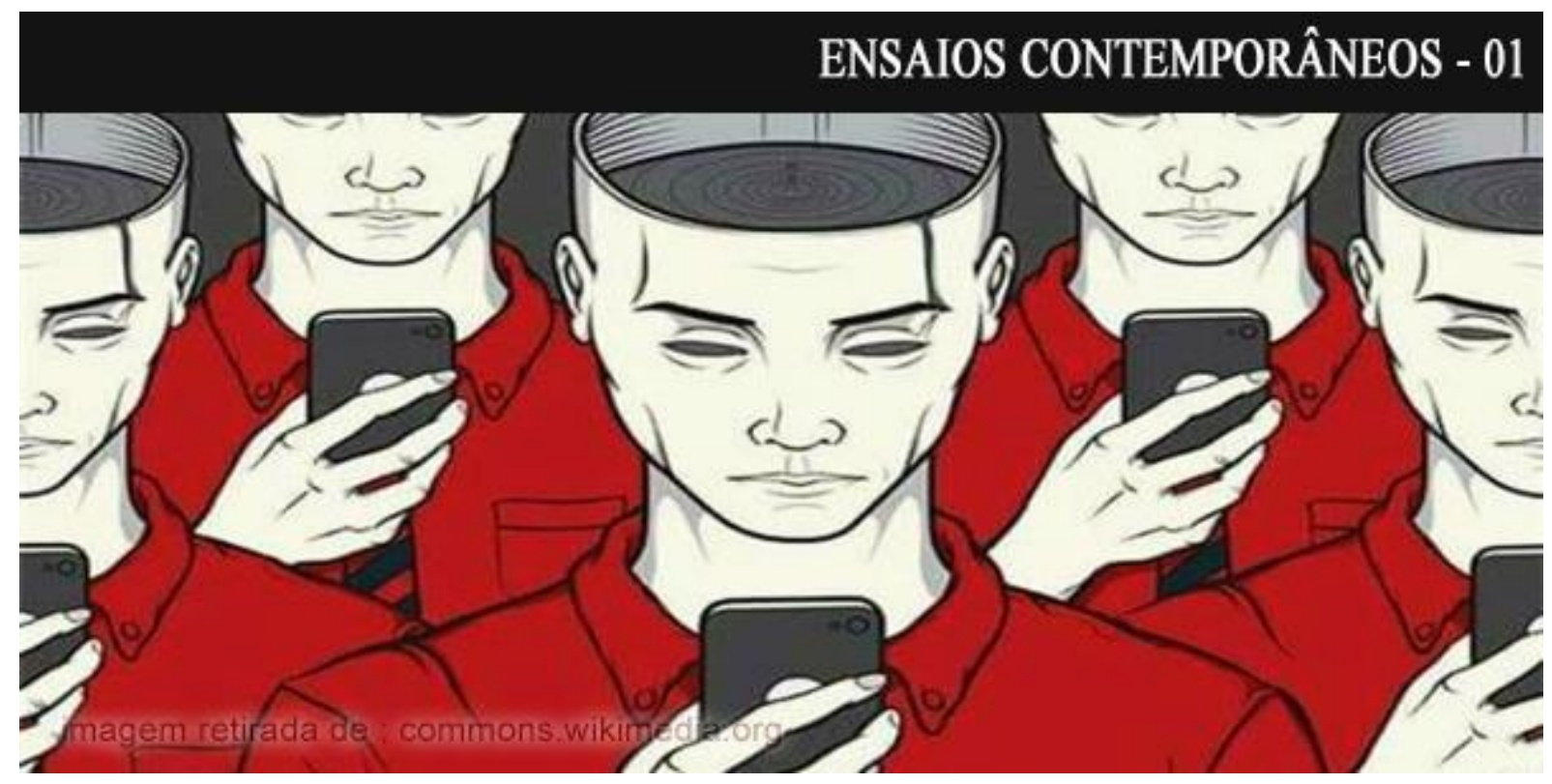

\title{
O INDIVÍDUO SOCIALMENTE FALHO: UM ENSAIO BASEADO EM VEBLEN E BAUMAN
}

\author{
Ronaldo Rangel \\ ORCID: https://orcid.org/0000-0003-0195-0481. \\ E-mail: rrrangel@fgvmail.br.
}

Gabriel Dolabela Raemy Rangel

ORCID: https://orcid.org/0000-0002-3000-5406.

Resumo: O ensaio revisita os livros A Teoria da Classe Ociosa (originalmente publicado em 1899), de Thorstein Veblen, e Modernidade Líquida, de Zygmunt Bauman, publicado pela primeira vez em 1999, os quais, embora separados por um século de história humana, observam as experiências sociais de seus respectivos tempos com constructos muito assemelhados. O ensaio assume que Veblen descreve efeitos da modernidade que emerge no fim do século XIX, ao passo que Bauman explicita a pós-modernidade do século XXI (à qual chama de Modernidade Líquida) e, com base nos autores, reflete sobre o indivíduo, as motivações de consumo, a demanda por crédito, o endividamento e outras categorias por eles tratadas, para apresentar um novo ator: o "consumidor falho" ou, como aqui chamado, o "indivíduo socialmente falho".

Palavras-chave: Consumo. Endividamento. Emulação pecuniária. Modernidade líquida.

\section{THE SOCIALLY FLAWED INDIVIDUAL: AN ESSAY BASED ON VEBLEN AND BAUMAN}

Abstract: The essay revisits the books The Theory of the Leisure Class (originally published in 1899) by Thorstein Veblen and Liquid Modernity by Zygmunt Bauman first published in 1999 that, although separated by a century of human history, observe social experiences from their respective times with very similar constructs. The essay assumes that Veblen describes the effects of modernity that emerged at the end of the 19th century, while Bauman explains the post-modernity of the 21st century (which he calls Liquid Modernity) and, based on the authors, reflects on the individual, the motivations consumption, the demand for credit, indebtedness and other categories treated by them, to present a new actor: the 'flawed consumers' or, how we conceptualize, a "socially flawed individual".

Keywords: Consumption. Indebtedness. Pecuniary emulation. Liquid modernity.

\section{POLÊM!CA | LABORE (3:}

Polêmica - Revista Eletrônica da Uerj - Rua São Francisco Xavier, 524, $1^{\circ}$ andar bloco D, sl.1001 • Tels.: +55 21 2334-4088 / 4087 • http://www.e-publicacoes.uerj.br/index.php/polemica/index http://www.labore.uerj.br • laboreuerj@yahoo.com.br 


\section{Introdução}

Estamos diante de um ambiente social totalmente novo. As últimas décadas criaram uma situação econômica, cultural e política, na qual se rompeu o pacto social tradicionalmente contratado, empurrando a sociedade para uma lógica de mercado focada na competição e no consumo, em que cidadania não é mais sinônimo de igualdade, de compromisso integrador, mas, sim, de diferenciação discriminatória. Vivemos uma falha no tecido social, pela qual o consumo nos diferencia e não consumir é ser socialmente falho.

A importância do tema proposto deve-se ao fato de estarmos vivendo, hodiernamente, diante de um consumismo exacerbado e do uso indiscriminado de crédito. Com efeito, as relações de consumo passaram a ter papel de destaque nas relações econômicas e sociais, atingindo, até mesmo, a própria esfera moral que norteia os valores da sociedade. O consumo, que em essência seria a forma de satisfazer as necessidades dos indivíduos, transformou-se em um comportamento para contemplar não necessidades, mas desejos que são criados de maneira incessante e que ganham ênfase frente à cultura do supérfluo e do descarte.

Para discutir tal condição, o ensaio aqui apresentado se vale de dois autores, Thorstein Veblen e Zygmunt Bauman, e, mais especificamente, da releitura de dois livros: A Teoria da Classe Ociosa (VEBLEN, 1987) e Modernidade Líquida (BAUMAN, 2001). Nessas obras, os autores, em momentos distintos, realizaram contundentes diagnósticos e análises sobre o fenômeno, sem, contudo, terem a pretensão de apontar alternativas. Na sua obra, Veblen o fez por meio do desenvolvimento da teoria da classe ociosa e Bauman, pela análise da modernidade por ele denominada líquida.

De pronto, cabe aqui salientar que seria bem pouco provável que dois pensadores tivessem construído projetos intelectuais tão parecidos, em momentos e sob condições tão distintas. Thorstein Veblen doutorou-se em Yale, enquanto os Estados Unidos viviam a reconstrução, mas, sobretudo, a ascensão econômica e a expansão dos níveis de consumo pósGuerra Civil (1861-1865), em que a tradicional relevância da agropecuária como fonte prioritária de renda nacional foi substituída pela força das indústrias manufatureira e bancária, possibilitando graus, sem precedentes, de prosperidade para aquele país e de riqueza, para certos segmentos de sua elite. Veblen é considerado um dos fundadores da escola institucionalista, sendo que sua obra aprimorou conceitos da tradição econômica, cuja descrição que ofereceu

\section{POLÊM!CA $\mid$ LABORE}

Polêmica - Revista Eletrônica da Uerj - Rua São Francisco Xavier, 524, $1^{\circ}$ andar bloco D, sl.1001 • Tels.: +55 21 2334-4088 / 4087 • http://www.e-publicacoes.uerj.br/index.php/polemica/index http://www.labore.uerj.br • laboreuerj@yahoo.com.br 
ainda é extremamente contemporânea como, por exemplo, a de financeirização da riqueza (CONCEIÇÃO, 2007).

Por seu turno, Zygmunt Bauman concluiu seus estudos em Varsóvia, durante o regime comunista do qual era adepto, tendo sido, inclusive, membro do serviço de segurança interno e militante ativo do PZRP (o Partido Comunista Polonês), até ser incluído, em 1968, no expurgo promovido pelo governo da Polônia, decorrente da reação a movimentos críticos ou revisionistas ao comunismo como, por exemplo, a Primavera de Praga. Com efeito, Bauman vivenciou os chamados movimentos de rebeldia do final dos anos sessenta, iniciados em países ocidentais (como os movimentos estudantis na França e o movimento pelos direitos civis nos EUA) e que se difundiram pelos países socialistas (a Primavera de Praga é seu exemplo mais emblemático) e, depois, pelo mundo. Pelo exposto, em consonância com seu tempo, Bauman abandonou sua visão ortodoxa do marxismo e aderiu ao chamado humanismo marxista (BAUMAN, 2017).

Como é de se perceber, são indivíduos e pensadores muito distintos que, não obstante, construíram um modo de olhar semelhante sobre a interpretação de aspectos da sociedade, já que realizam uma análise de caráter macro, baseando-se, em certo sentido, em explicações sobre o comportamento micro, quase numa dimensão de psicologia da conduta individual. Não deixa de ser curioso que Veblen tenha desenvolvido sua acepção de mundo em um momento em que os Estados Unidos não só vivenciavam sua modernização, mas, antes de tudo, passavam pelo fenômeno da modernidade que, como esclarece Raimundo Faoro, envolve toda a sociedade:

[...] a modernidade compromete, no seu processo, toda a sociedade, ampliando o raio de expansão de todas as classes, revitalizando e removendo seus papéis sociais, enquanto que a modernização, pelo seu toque voluntário, se não voluntarista, chega a sociedade por meio de um grupo condutor, que se privilegiando, privilegia os setores dominante (FAORO, 1992, p. 8).

Já Zygmunt Bauman experimentou a pós-modernidade, mesmo que o autor tenha preferido, como veremos adiante, o termo Modernidade Líquida, em contraposição ao conceito de pós-modernidade que, usualmente, costuma-se empregar. Destaca-se que, se há uma definição controversa, essa é a de pós-modernidade, embora algumas de suas características possam ser resumidas em pontos geralmente aceitos de forma ampla, tais como: domínio pelas mídias eletrônicas; foco exacerbado nos mercados (econômico e cultural); pluralidade cultural,

\section{POLÊM!CA $\mid$ LABORẸ}

Polêmica - Revista Eletrônica da Uerj - Rua São Francisco Xavier, 524, $1^{\circ}$ andar bloco D, sl.1001 • Tels.: +55 21 2334-4088 / 4087 • http://www.e-publicacoes.uerj.br/index.php/polemica/index http://www.labore.uerj.br • laboreuerj@yahoo.com.br 
radicalismo étnico etc. (FREITAS, 2012); e o que aqui mais interessa: a celebração do consumo como expressão de mobilidade pessoal.

Nesse contexto, para Bauman, os consumidores ou, se preferirmos o consumo, têm papel fundamental na modernidade, pois o "tipo de sociedade que promove, encoraja ou reforça a escolha de um estilo de vida e uma estratégia existencial consumistas e rejeita todas as opções culturais alternativas" (BAUMAN, 2008, p. 71). Por isso, o indivíduo deve cumprir o seu desígnio social primordial na sociedade contemporânea que é ser um consumidor ativo e exemplar, já que sua posição na escala social é definida (ou avaliada) por sua capacidade de consumir.

Em sentido distinto mas, como se retende demonstrar, congruente, Veblen considera que a posição do indivíduo, na escala social, se dá pelo seu nível de ócio, ou seja, pelo fato de que não é necessário esforço para gerar riqueza ou renda.

\footnotetext{
A desnecessidade de trabalhar não é só algo honorífico e meritório; muito cedo tornase um requisito de decência. Durante os primeiros tempos da acumulação de riqueza, a insistência na propriedade, como base de respeitabilidade, é extremamente ingênua e imperiosa. Esta desnecessidade de trabalhar é a prova convencional de riqueza, sendo portantoa marca convencional de posição social; e essa insistência sobre o mérito da riqueza leva a uma insistência sobre o ócio (VEBLEN, 1987, p. 25).
}

Como se percebe, se para Bauman o consumo determina a identidade social de cada indivíduo, para Veblen os valores centrados no ócio é que criam o aspecto fundamental da identidade em sociedade, já que a propriedade se torna a base da estima social.

Prometendo retomar o tema à frente, é imprescindível adiantar que Veblen considera que de pouco vale possuir propriedades e viver em ócio, se não for possível ostentar tal situação, o que leva a um consumo ostensivo, que, por sua vez, é invejado por grupos sociais de menor renda (incluindo, mesmo, os de baixa renda) que tentam, indo além de sua capacidade financeira, também consumir de forma intensiva.

Já Bauman entende que a sociedade contemporânea é constituída pelo imperativo do consumo e, por óbvio, não no sentido de cobrir necessidades relativas ao bem-estar e à razoabilidade da satisfação como, por exemplo, pela durabilidade dos bens e pela segurança de um fluxo regular de consumo. Ao contrário, para ele, o consumo é impulsivo, motivado por uma satisfação imediata e por uma onipotência do querer, que se tornam incessantes, transformando o consumo em consumismo.

Para levar a cabo a tarefa a que se propõe, este texto está dividido em cinco partes além

\section{POLÊM!CA $\mid$ LABORE}

Polêmica - Revista Eletrônica da Uerj - Rua São Francisco Xavier, 524, $1^{\circ}$ andar bloco D, sl.1001 • Tels.: +55 21 2334-4088 / 4087 • http://www.e-publicacoes.uerj.br/index.php/polemica/index http://www.labore.uerj.br • laboreuerj@yahoo.com.br 
da presente introdução. Na primeira, pretende-se justificar a escolha por um ensaio para apresentar o tema. As duas seguintes buscam apresentar alguns conceitos fundamentais para o tema presente nas obras de Veblen e Bauman. Sempre valendo-se dos dois autores, a quarta parte procura refletir sobre indivíduo e comportamento consumista com endividamento. Por fim, embora deixando claro que não pretende ser conclusivo, o ensaio apresenta alguns comentários à guisa de considerações finais.

\section{A escolha por um Ensaio: uma explicação necessária}

Em artigo, o escritor britânico G. K. Chesterton atesta que ensaio é algo díspar explicando que:

[...] um ensaio, com seu próprio nome e sua própria natureza, é verdadeiramente uma tentativa e um experimento. Na verdade, não se escreve um ensaio. O que se faz é ensaiar um ensaio. E o resultado é que, embora existam muitos ensaios famosos, felizmente, não há ensaio modelo. O ensaio perfeito nunca foi escrito, pela simples razão de que o ensaio nunca se escreve (CHESTERTON, 2007, p. 23, tradução nossa).

Confirmando a assertiva de Chesterton, o professor colombiano Jesús Antonio Álvarez Flórez assegura: "Nenhum ensaio será concluído enquanto o autor tenha algo mais a dizer sobre o assunto" (FLÓREZ, 2019, p. 61, tradução nossa). E propõe "pensá-lo como uma produção que privilegia um ponto de vista, que não pretende ser exaustivo, muito menos, abrangente em todos os seus vértices" (ibidem).

Não deixa de ser curioso que, no fim dos anos 1920, Virginia Woolf tenha publicado Street Haunting and other Essays (2014), no qual argumenta que os ensaios resistem a serem definidos teoricamente, alertando, contudo, que, exatamente por essa razão, eles sempre precisam se explicar. Além disso, em seu livro, Woolf nos oferece treze descrições do ensaio, dentre elas, destaca-se o ensaio como aprendizado.

Com efeito, enquanto desenvolve seu ensaio, o ensaísta aprende. Assim, como em todo aprendizado, pode-se afirmar que quando da concepção de um ensaio não há espaço para afirmações definitivas, mas há sim ambiente para a manifestação de dúvidas e reflexões.

O aparecimento do ensaio está relacionado ao nome de Michel Montaigne, autor do livro Ensaios (sendo o título original Les Essais), de 1580, e criador do gênero que é marcado por visões pessoais e reminiscências. Se tomarmos o significando da própria palavra "essais", vamos constatar que ela significa "tentativa". Detalhando o termo, Kazue Saito de Barros,

\section{POLÊM!CA $\mid$ LABORE}

Polêmica - Revista Eletrônica da Uerj - Rua São Francisco Xavier, 524, $1^{\circ}$ andar bloco D, sl.1001 • Tels.: +55 21 2334-4088 / 4087 • http://www.e-publicacoes.uerj.br/index.php/polemica/index http://www.labore.uerj.br • laboreuerj@yahoo.com.br 
preleciona que: "Etimologicamente, relacionado aos termos latinos exagium (pesar) e exigere (testar) e, em francês, a essayer (colocar à prova) e essai (tentativa) o termo ensaio carrega a ideia de tentativa de ação especulativa e interpretativa" (BARROS, 2011, p. 335).

Neste sentido, todo ensaio, inclusive os acadêmico-científicos, tem caráter experimental, o que não altera a necessidade de que um ensaio acadêmico deve estar organizado de forma argumentativa e fornecer uma reflexão sólida, apoiada por evidências relevantes, normalmente, advindas de outros trabalhos, estudos ou de pesquisas.

Há um pequeno texto intitulado Artigos e Ensaios Científicos (BRITO, 2001), no qual a autora apresenta dois tipos de ensaios científicos: informativo ou teórico e opinativo ou avaliativo. A par de pequenas diferenças de forma, o texto assegura que, no primeiro tipo, o autor do ensaio busca convencer o leitor e, no outro, objetiva a persuasão. Dito de outra maneira, no ensaio teórico o argumento se sustenta em fatos do domínio científico ao passo que no “[...] ensaio avaliativo, confrontam-se experiências conhecidas pelo ensaísta que são comparadas, apreciadas, julgadas e transmitidas à comunidade científica, a fim de que esta mude de opinião e aceite o ponto de vista do escritor ensaísta" (BRITO, 2001, p. 113).

Assim, quando nos deparamos com um texto no qual não se enfatizam dados científicos e elementos do saber culto são tratados intuitivamente, estamos diante de um ensaio avaliativo (ou opinativo). Nesse contexto, o ensaio avaliativo: "[...] oferece uma discussão e "insight" sobre uma questão científica de interesse atual. Neste caso, não se lida com resultados de pesquisa original, mas se recorre a materiais já publicados ou material de conferência" (PAGLIUCHI DA SILVEIRA, 1999, p. 35).

Um ensaio avaliativo é o objetivo deste trabalho, o qual busca aprofundar a reflexão do ensaísta e, simultaneamente, despertar a reflexão do leitor sobre a dinâmica do consumo como realização pessoal e instrumento de socialização e o não consumo como imputador de falhas sociais ao indivíduo. É um exame inconcluso, mas que pelo qual se pretende provocar reflexões e aprender sobre a realidade social desenhada.

\section{Consumo, Crédito e Emulação em Veblen}

Em 1899, Thorstein Veblen publica o livro A Teoria da Classe Ociosa, alertando, já nas primeiras páginas, que o termo ócio não é sinônimo de preguiça (ou em suas palavras, indolência) mas de tempo utilizado em atividade não produtiva. Segundo ele, o ócio de grupos

\section{POLÊM!CA | LABORE}

Polêmica - Revista Eletrônica da Uerj - Rua São Francisco Xavier, 524, $1^{\circ}$ andar bloco D, sl.1001 • Tels.: +55 21 2334-4088 / 4087 • http://www.e-publicacoes.uerj.br/index.php/polemica/index http://www.labore.uerj.br・ laboreuerj@yahoo.com.br 
abastados decorre de certa visão de que o trabalho é indigno, pois quem o realiza é o outro (no passado o escravo, o servo e, no período em tela, o assalariado, o subalterno) e, ademais, serve para demonstrar a habilidade decorrente de renda e posses, que permita viver uma vida inativa em termos produtivos.

Essencialmente, Veblen confronta a tese do comportamento racional, proposta pelos modelos matemáticos dos teóricos neoclássicos, apontando que essa hipotética racionalidade muito pouco tem a ver com os efetivos processos que moldam e mobilizam a sociedade, dado que elementos culturais, a formação histórica e, mesmo questões psicológicas, influenciam mais o indivíduo, mormente, o capitalista, do que qualquer prática econômica maximizadora.

Considerando que os valores sociais se estabelecem com base no ócio e na possibilidade de consumir sem exercer atividade produtiva, segundo o autor, surge o interesse de ostentar o ócio, pois "todo sentido de gastar dinheiro estava em impressionar os outros" (STRATHERN, 2003, p. 211). Assim, se estabelece a busca contínua de comparação do indivíduo em relação à força pecuniária do resto da comunidade com a qual convive.

Por óbvio, para Veblen, através da força pecuniária, o indivíduo elevava sua reputação ou seu prestígio social e adquiria, como consequência, um valor de caráter comercial, o que lhe permitia, no limite, obter crédito junto à sua comunidade, já que a força e a capacidade pecuniária

[...] indicam, na realidade, que o usuário possui capacidade pecuniária ou força pecuniária, isto é, habilidade de pagar, despender ou desperdiçar; e sendo estes os valores essenciais das sociedades pecuniárias, o que o usuário obtém, consequentemente, é - valor ou apreciação comercialll, reputação elevada, prestígio, ou good-will; e, em última instância, obtém ou eleva seu crédito junto à comunidade (CRUZ, 2014, p. 183).

Pelo exposto, passa a existir no sujeito - independentemente de sua classe social ou nível de renda - o desejo de estar sempre acima do padrão médio de consumo, pois a “comparação odiosa é o processo de estimativa das pessoas relativamente ao seu valor" (VEBLEN, 1987, p. 295), ou seja, despertar a inveja das pessoas e grupos próximos aumenta a sensação de importância que se tem de si mesmo. Tal comportamento cria o que Veblen conceituou como emulação pecuniária, na verdade, uma disputa de egos, em que cada um tenta mostrar seu poder (pela citada força pecuniária), em uma busca ininterrupta para atingir uma posição social de honorabilidade pecuniária (VEBLEN, 1987, p. 54) ou, em outras palavras:

\section{POLÊM!CA | LABORE}

Polêmica - Revista Eletrônica da Uerj - Rua São Francisco Xavier, 524, $1^{\circ}$ andar bloco D, sl.1001 • Tels.: +55 21 2334-4088 / 4087 • http://www.e-publicacoes.uerj.br/index.php/polemica/index http://www.labore.uerj.br • laboreuerj@yahoo.com.br 


\begin{abstract}
A fim de impressionar esses observadores efêmeros e a fim de manter a satisfação própria em face da observação deles, a marca da força pecuniária das pessoas deve ser gravada em caracteres que, mesmo correndo, se possa ler. É, portanto, evidente que a presente tendência do desenvolvimento vai na direção de aumentar, mais que o ócio, o consumo conspícuo (VEBLEN, 1987, p. 321).
\end{abstract}

Pelo exposto, o citado consumo conspícuo é realizado com a finalidade precípua de demonstrar a condição social por meio da compra de artigos de luxo, de gastos ostentatórios e, mesmo, pelo desperdício. Ocorre, como vimos, que indivíduos de certo estrato social procuram copiar padrões de comportamento de camadas superiores, tentando demonstrar um status que não possuem. Assim, o consumo conspícuo é perpetrado por todas as classes e estratos da sociedade.

\title{
Individualismo na Modernidade Líquida de Bauman
}

No livro publicado em 2000, Modernidade Líquida, Bauman diagnostica a mudança da sociedade sólida para a líquida. Como vimos, ao invés de usar a expressão pós-modernidade, o autor preferiu a metáfora da liquidez para descrever os tempos atuais. Essa liquidez representa uma sociedade que tem melhor adaptação aos meios, no preenchimento de um ambiente, e, com a mesma facilidade, se esvai, tomando outras formas. Em uma sociedade sólida, não se conseguia o preenchimento de um ambiente que não fosse de sua forma pré-definida. Hoje, vive-se um mundo repleto de desordens, propenso a mudar com rapidez, de forma imprevisível. As pessoas passam a simplesmente buscar sua autorrealização em um modelo de individualidade. Nesse ponto, o autor faz um importante destaque na passagem do modelo fordista (com produção padronizada e clara divisão do trabalho), que chamou de capitalismo pesado, para o pós-fordismo (flexível, intensivo em tecnologia e poupador de mão-de-obra), que denominou capitalismo leve.

No capitalismo pesado, os trabalhadores viviam com correntes invisíveis, com uma definição bem clara de líderes e patrões, não existindo uma real liberdade de escolhas, frente às mecânicas de padronização da produção. A passagem ao capitalismo leve é marcada justamente pelo advento da flexibilidade e, portanto, de uma maior liberdade de escolhas. No capitalismo leve, os prelados do capital tentam seduzir e se tornar agradáveis às pessoas que escolhem.

De toda forma, as escolhas são individuais e a individualidade é um dos pilares da modernidade líquida. A própria figura do livro de autoajuda, trazida pelo autor, é um ótimo exemplo disso. Devemos nos preocupar em resolver os nossos problemas, já que "há pouco a

\section{POLÊM!CA $\mid$ LABORE}

Polêmica - Revista Eletrônica da Uerj - Rua São Francisco Xavier, 524, $1^{\circ}$ andar bloco D, sl.1001 • Tels.: +55 21 2334-4088 / 4087 • http://www.e-publicacoes.uerj.br/index.php/polemica/index http://www.labore.uerj.br • laboreuerj@yahoo.com.br 
ganhar fazendo o trabalho dos outros, e isso desviaria nossa atenção do trabalho que ninguém pode fazer se não nós mesmos” (BAUMAN, 2001, p. 85). De outro lado, a individualidade é constituída pelo imperativo do consumo, pela prevalência do querer, prática essa incessante. Hoje, o consumo (como condição natural da sobrevivência) dá lugar ao consumismo, que não é relacionado às necessidades que o homem tem. Ao revés, a prática do consumismo atrela-se aos desejos:

O spiritus movens da atividade consumista não é mais o conjunto mensurável de necessidades articuladas, mas o desejo - entidade muito mais volátil e efêmera, evasiva e caprichosa, e essencialmente não referencial que as necessidades, um motivo autogerado e autopropelido que não precisa de outra justificação ou causa (BAUMAN, 2001, p. 96).

Essa necessidade de consumir se relaciona com a cultura do rejeite, do substituível ou do provisório, pois, para que a sociedade incessantemente permaneça consumindo, tendo desejos, faz-se necessária a prática continua de descarte:

\begin{abstract}
A história do consumismo é a história da quebra e descarte de sucessivos obstáculos sólidos que limitavam o voo livre da fantasia e reduzem o princípio do prazer ao tamanho ditado pelo princípio da realidade. A necessidade, considerada pelos economistas do século XIX como a própria epítome da solidez - inflexível, permanentemente circunscrita e finita - foi descartada e substituída durante algum tempo pelo desejo, que era muito mais fluído e expansível que a necessidade por causa de suas relações meio ilícitas com sonhos plásticos e volúveis sobre a autenticidade de um eu íntimo à espera de expressão. Agora é a vez de descartar o desejo (BAUMAN, 2001, p. 97-98).
\end{abstract}

Portanto, a fim de estimular a cultura do descarte, estabelece-se um modelo de prazos de validade, tornando tudo obsoleto em curto tempo. É o que se conhece por obsolescência programada. Viviane Monteiro ensina que "o conceito da obsolescência planejada, em seus primórdios, era baseado no Homo economicus, ou seja, na ideia que o ser humano tem habilidades infinitas de fazer decisões puramente racionais. Portanto, a redução da vida útil de um produto forçaria os consumidores a fazer repetidas compras" (MONTEIRO, 2019, p. 46).

Zygmunt Bauman, na obra Vida para Consumo: a transformação das pessoas em mercadorias (2008), distingue a sociedade de produtores (período sólido) da sociedade do consumismo. Buscava-se, na sociedade de produtores, bens duradouros, que fossem úteis por um longo prazo. As pessoas buscavam acumular bens duráveis e isso gerava a sensação de garantia, conforto, segurança. O ser humano não visava a um consumo só imediato, mas estabilidade e segurança: "Na era sólido-moderna da sociedade de produtores, a satisfação

\title{
POLÊM!CA $\mid$ LABORE
}

Polêmica - Revista Eletrônica da Uerj - Rua São Francisco Xavier, 524, $1^{\circ}$ andar bloco D, sl.1001 • Tels.: +55 21 2334-4088 / 4087 • http://www.e-publicacoes.uerj.br/index.php/polemica/index http://www.labore.uerj.br • laboreuerj@yahoo.com.br 
parecia de fato residir, acima de tudo, na promessa de segurança a longo prazo, não no desfrute imediato de prazeres" (BAUMAN, 2008, p. 43).

$\mathrm{Na}$ era líquida, de outra ponta, o desejo de segurança se perde. Passa-se a condutas impulsivas e imediatistas de ânsia por consumo, sem a preocupação com a durabilidade do que se adquire. A satisfação individual não repousa mais nessa estabilidade dos bens duráveis, mas na satisfação imediata de desejos sempre crescentes. Vive-se uma rotina em que grandes oportunidades não param de surgir e sente-se uma necessidade interminável de aproveitá-las, como se "cada ponto do tempo seja impregnado da possibilidade de um novo Bigbang" (BAUMAN, 2008, p. 46). Como consequência, tem-se uma sociedade apressada, sendo que se a cada ponto no tempo surge uma oportunidade única, para qual não existirá uma segunda chance, não se pode conceber demoras.

[...] a vida agorista tende a ser apressada. A oportunidade que cada ponto pode conter vai segui-lo até o túmulo; para aquela oportunidade única não haverá segunda chance. Cada ponto pode ter sido vivido como um começo total e verdadeiramente novo, mas se não houver um rápido e determinado estimulo à ação instantânea, a cortina pode ter caído logo após o começo do ato, com pouca coisa acontecendo no intervalo. A demora é o serial killer das oportunidades (BAUMAN, 2008, p. 50).

A vida passa a ser norteada pelo agora. Não há tempo sobrando e existe uma inflação enorme de informações. Como consequência, o bem mais escasso passa a ser a atenção do consumidor (BAUMAN, 2008). Nesse ponto, Anthony Giddens (1991) bem sustentou que, na modernidade, caracterizada por um desencaixe entre tempo e espaço, tem-se uma postura de não querer e poder nos informar sobre tudo e, agindo pragmaticamente, passa-se a confiar em sistemas de peritos, mais ou menos na ideia de que, em algumas oportunidades, não é preciso saber de algo se é possível pagar a alguém que tem conhecimento técnico sobre aquilo. Nesse diapasão, Giddens afirma que

O respeito pelo conhecimento técnico existe comumente em conjunção com uma atitude pragmática para com sistemas abstratos, baseada em atitudes de ceticismo ou reserva. Muitas pessoas, por assim dizer, fazem uma barganha com a modernidade em termos de confiança que concedem às fichas simbólicas e sistemas peritos (GIDDENS, 1991, p. 93).

A Modernidade Líquida, portanto, é cenário marcado pelo individualismo, pelo excesso de informações, pelo impulso no consumo e pelo descarte constante de coisas.

\section{POLÊM!CA $\mid$ LABORE}

Polêmica - Revista Eletrônica da Uerj - Rua São Francisco Xavier, 524, $1^{\circ}$ andar bloco D, sl.1001 • Tels.: +55 21 2334-4088 / 4087 • http://www.e-publicacoes.uerj.br/index.php/polemica/index http://www.labore.uerj.br • laboreuerj@yahoo.com.br 


\section{Indivíduo, Consumismo e Endividamento}

Como já salientado, o consumismo é marco central da Modernidade Líquida diagnosticada por Bauman, em que os desejos - que não param de surgir - fazem com que as pessoas permaneçam em constante procura de bens e serviços, de maneira descontrolada e imediatista. Por seu turno, Veblen alerta para a tendência da emulação pecuniária e do consumo conspícuo. Assim, em um caso ou em outro, a todo momento, nascem novas necessidades, advindas de novas mercadorias, que, por sua vez, são substituídas por outras mercadorias, que inspiram novos desejos e novas necessidades, que serão copiados por todos os estratos sociais, em um ciclo inesgotável. Esse comportamento desenfreado e irrefletido não é compatível, por óbvio, com uma conduta planejada e responsável em relação aos recursos disponíveis.

Em uma sociedade em que valores e mobilidade estão atrelados ao consumismo, possuir coisas modernas e aparentar ter possibilidade de consumo permanente é fundamental. Existe um grande imaginário envolvido no potencial de consumo, representando um status social.

Como consequência, consumir de forma intensa gera sentimento de orgulho, ao passo que adquirir bens ultrapassados ou ter consumo restrito provoca sentimento de vergonha. Esse cenário é sobremaneira agravado pela falta do que se pode chamar de visão intertemporal dos consumidores, que assumem que podem consumir hoje, arcando com crédito, o que significa utilizar recursos ou renda futura. Creem que permanecerão no emprego, que não acontecerão eventos imprevisíveis. Essa crença os torna presas mais fáceis do endividamento. Há um vínculo umbilical entre a difusão da concessão de crédito e não só o endividamento, mas de um superendividamento, como bem afirma Clarissa Costa de Lima:

Em quase todo o mundo, a democratização do crédito veio acompanhada do aumento do superendividamento dos consumidores tanto em países com economias desenvolvidas e que contam com sistema maduro de falência, como em países em desenvolvimento cujo ordenamento não prevê a possibilidade de falência de pessoas físicas (LIMA, 2014, p. 33).

A manipulação do mercado instiga ainda mais os desejos dos consumidores que, como já salientado, não são racionais e, pelo contrário, para consumir nos padrões sociais desejáveis se mobilizam por razões emocionais e se deixam envolver pelo assédio do marketing e suas técnicas que, em muitos casos, podem ser consideradas agressivas, levando-os a um consumo exagerado e a um endividamento disfuncional. Nas palavras de Adriana Carvalho Pinto Vieira, Daiane Kachuba e Liliana Locatelli,

\section{POLÊM!CA $\mid$ LABORE}

Polêmica - Revista Eletrônica da Uerj - Rua São Francisco Xavier, 524, $1^{\circ}$ andar bloco D, sl.1001 • Tels.: +55 21 2334-4088 / 4087 • http://www.e-publicacoes.uerj.br/index.php/polemica/index http://www.labore.uerj.br • laboreuerj@yahoo.com.br 
[...] a vulnerabilidade comportamental tem uma relação direta com a manipulação do mercado. E, sendo assim, a prevenção do superendividamento por meio de normas jurídicas ou pela promoção de políticas públicas não pode deixar de incluir o reconhecimento de que o consumidor está exposto constantemente às estratégias publicitárias e de marketing por parte dos fornecedores, pois os mesmos possuem técnicas para identificar os principais problemas cognitivos que os afetam, explorando esta fragilidade, e incentivando desenfreadamente o consumo dos produtos e dos serviços (PINTO VIEIRA; KACHUBA; LOCATELLI, 2020, p. 5-6).

Destaque-se que Bauman chama a atenção de que a modernidade líquida aproxima a ideia de luxo do sentido de necessidade, afirmando que "a ideia é fazer dos luxos de hoje as necessidades de amanhã e reduzir a distância entre o hoje e o amanhã ao mínimo" (BAUMAN, 2001, p. 99). Em outros termos, Veblen também associa a ideia de luxo ao conceito de necessidade:

O qualificativo - necessidade - merece atenção. Existe uma quantidade considerável de privação física sofrida por muitas pessoas neste país que não são fisicamente indispensáveis. A causa muito frequente é que o que deveriam ser os meios de conforto encontram-se desviados para propósitos de manutenção de uma aparência decente, ou mesmo a demonstração de algum luxo. (VEBLEN, 1891, p. 392, tradução nossa).

De toda maneira, independentemente da real necessidade, o crédito permite não apenas transformar o luxo, como aqui conceituado, em algo acessível, mas, por meio dele, desejos diversos viram realidades, portanto, com o crédito se pode ter muito do que se deseja. Sucede que, como dito, o ciclo de desejo é inesgotável, já que a sociedade de consumo é movida por uma insatisfação contínua de consumo. Note-se que a promessa de satisfação somente é sedutora enquanto a insatisfação se mantém existindo. Desse modo, “[...] é exatamente a não satisfação dos desejos e convicções inquebrantável, a toda hora renovada e reforçada, de que cada tentativa de satisfazê-los fracassou no todo ou em parte que constituem os verdadeiros volantes da economia voltada para o consumo" (BAUMAN, 2008, p. 63-64).

A consequência natural desse ciclo é o incessante consumo e a também incessante busca ao crédito, marcando uma era de pessoas endividadas. Assim, ao mesmo tempo em que o endividamento é consequência de um padrão de sociabilidade e de inclusão a ele inerente, também representa a perda dessa mesma sociabilidade e da inclusão social almejada, caso não seja obtido, pois, como já salientado, são os padrões de consumo que determinam a identidade de cada indivíduo, que é reconhecido pelo crédito que dispõe e pelo que consome, sendo que não consumir é ser excluído socialmente.

As pessoas classificadas como "subclasse" são condenadas à exclusão social e

\section{POLÊM!CA $\mid$ LABORE}

Polêmica - Revista Eletrônica da Uerj - Rua São Francisco Xavier, 524, $1^{\circ}$ andar

bloco D, sl.1001 • Tels.: +55 21 2334-4088 / 4087 • http://www.e-publicacoes.uerj.br/index.php/polemica/index

http://www.labore.uerj.br • laboreuerj@yahoo.com.br 
consideradas incapazes de se afiliarem a uma sociedade que exige que seus membros participem do jogo do consumismo segundo as regras estabelecidas, justamente porque são, tal como os ricos e abastados, abertos às seduções muito bem amparadas do consumismo - embora, de forma distinta dos abastados e dos ricos, não possam de fato se dar ao luxo de serem seduzidos (BAUMAN, 2008, p. 176).

Sendo dado que aquilo que define a pirâmide social é a capacidade efetiva de consumir, deve-se ter claro que consumir não é uma possibilidade aberta e abrangente. Estar disposto a consumir não implica em acesso ao consumo que, com efeito, é destinado a poucos (portadores de renda ou crédito), o que estabelece uma lógica da exclusão. Bauman chama aqueles que não possuem os recursos necessários para atender aos incessantes apelos de consumo de consumidores falhos. São os excluídos, os pobres, os marginalizados e, no limite, os que pelo não consumo têm a imagem criminalizada.

Para a sociedade, o consumo, embora sempre insatisfeito e em constante transformação, é inclusivo, equivale à garantia de socialização do indivíduo que, ao possuir (ou consumir) bens, demonstra ser, simultaneamente, diferenciado e integrado. Como vimos, há técnicas de marketing, publicidade etc., que incentivam a pessoa a consumir de tudo, mesmo que de forma conspícua, por meio de crédito, sendo que, para o indivíduo, consumir é uma forma de mobilidade social, de distanciamento da marginalização da pobreza e, portanto, de deixar de ser socialmente falho.

\section{Considerações finais: algumas reflexões do ensaio}

Separados por um século, Thorstein Veblen e Zygmunt Bauman apresentam, em suas obras, radiografias da sociedade de seu tempo, mas que, em grande medida, convergem, ainda que com traços distintos, para um desenho semelhante.

Em sociedades pecuniárias como explicitadas por Veblen, ou na sociedade moderna líquida, definida por Bauman, o consumo e a busca da realização patrimonial não se relacionam com a satisfação objetiva das necessidades, mas são motivadas pela busca de uma satisfação subjetiva, focada na obtenção ou elevação de status, ou seja, na aceitação ou reconhecimento social. Assim, pode-se admitir que a sociedade (no passado e, ainda, hoje) convive com a peculiaridade de que, independente de coletivamente haver níveis produtivos elevados e mesmo a obtenção de alguma abundância material, para os indivíduos o que se estabelece é a sensação psicológica de escassez permanente.

\section{POLÊM!CA $\mid$ LABORE}

Polêmica - Revista Eletrônica da Uerj - Rua São Francisco Xavier, 524, $1^{\circ}$ andar bloco D, sl.1001 • Tels.: +55 21 2334-4088 / 4087 • http://www.e-publicacoes.uerj.br/index.php/polemica/index http://www.labore.uerj.br • laboreuerj@yahoo.com.br 
Essa sensação generalizada de carência econômica e de desconforto psicológico cria uma espécie de círculo vicioso de consumo que, por sua vez, é instado pelo reconhecimento honorífico derivado do consumo conspícuo, pela obsolescência programada de bens e serviços e pela pretensão de felicidade associada ao ato de adquirir coisas novas. Isso, combinado à relativa fácil possibilidade de obtenção de crédito, gera, inexoravelmente, uma sociedade endividada.

Tal fenômeno pode ser explicado na constatação de que, a despeito do vigor e virtuosidade no consumo, os indivíduos jamais alcançam a satisfação objetiva de suas necessidades, pois as possibilidades de reposição ou atualização de produtos e, por conseguinte, as comparações de status sociais decorrentes de tal consumo, são virtualmente infinitas.

Destaque-se, por fim, que o conjunto da obra de Veblen sugere que mecanismos institucionais podem, ocasionalmente, vir a prevalecer sobre o autointeresse (CRUZ, 2014), ao passo que a obra de Bauman questiona essa possibilidade, já que para ele "as instituições democráticas não foram estruturadas para lidar com situação de interdependência" (BAUMAN, 2016). De toda sorte, observa-se claramente que, para os dois pensadores, o objetivo prioritário do indivíduo nas sociedades com cultura consumista é obter consumo, visando estabelecer prestígio e autopromoção, ou se preferirmos, não ser socialmente falho.

Assim, longe de se pretender esgotar as possibilidades de interpretação derivadas da leitura dos citados livros de Veblen e de Bauman, pode-se deixar em aberto a reflexão de que a modernidade vivenciada por um e a pós-modernidade exposta pelo segundo não se contrapõem no que tange ao estabelecimento de hábitos predatórios inerentes à sociedade na qual, pelos dois olhares, prevalecem o interesse individual, a cultura do descarte e do desperdício, a busca por ampliar consumo e propriedade e, portanto, os alicerces de uma condição competitiva entre indivíduos.

\section{Referências}

BARROS, K. S. M. Réplica 1 - o que é um ensaio? Revista de Administração Contemporânea, ANPAD, Curitiba, v. 15, n. 2, p. 333-337, mar./abr. 2011.

BAUMAN, Z. Modernidade Líquida. Rio de Janeiro: Zahar, 2001.

BAUMAN, Z. Vida Para Consumo: A transformação das pessoas em mercadorias. Rio de Janeiro: Zahar, 2008.

BAUMAN, Z. Morre Zygmunt Bauman. Leia entrevista inédita em que ele defende a redenção pelo diálogo. Entrevista concedida a Guilherme Evelin e Ruan de Sousa Gabriel. Revista Época, São Paulo, n. 976, p. 5-8, 9

\section{POLÊM!CA $\mid$ LABORẸ}

Polêmica - Revista Eletrônica da Uerj - Rua São Francisco Xavier, 524, $1^{\circ}$ andar bloco D, sl.1001 • Tels.: +55 21 2334-4088 / 4087 • http://www.e-publicacoes.uerj.br/index.php/polemica/index http://www.labore.uerj.br • laboreuerj@yahoo.com.br 
jan. 2017. Disponível em: https://epoca.globo.com/cultura/noticia/2017/01/morre-zygmunt-bauman-leiaentrevista-inedita-em-que-ele-defende-redencao-pelo-dialogo.html. Acesso em: 21 jan. 2020.

BAUMAN, Z. Las redes sociales son una trampa. Entrevista concedida a Ricardo de Querol. El Pais (digital), Burgos (Espanha), 8 de fev. 2016. Disponível em:

https://cultura.elpais.com/cultura/2015/12/30/babelia/1451504427_675885.html. Acesso em: 05 fev. 2020.

BRITO, V. Artigos e Ensaios Científicos. RDE - Revista de Desenvolvimento Econômico, Salvador, UNIFACS, ano 3, n. 4, p. 122-123, jul. 2001.

CASADEI, E. B. Muito além do líquido: modernidade, ideologia e cultura na obra de Zygmunt Bauman. Revista Espaço Acadêmico, Maringá, UEM, v. 9, n. 102, p. 81-88, nov. 2009.

CHESTERTON, G. K. On Running After One's Hat and Other Whimsies. London: Maudsley Press, 2007.

CONCEIÇÃO, O. Além da Transação: uma comparação do pensamento dos institucionalistas com os evolucionários e pós-keynesianos. EconomiA, ANPEC, Brasília, v. 7, n. 3, p. 621-642, set./dez. 2007.

CRUZ, M. Thorstein Veblen. O teórico da Economia Moderna. Editado pelo autor, 2014. E-book. Disponível em: https://sites.google.com/site/murillocruzfilho/home/thorstein-veblen---o-teorico-daeconomia-moderna Acesso em: 03 fev. 2020.

FAORO, R. A questão nacional: a modernização. Estudos Avançados, São Paulo, USP, v. 6, n. 14, p. 7-22, 1992.

FLÓREZ, J. A. A. ¿Qué es el Ensayo? Revista La Tercera Orilla, Bucaramanga (Colômbia), UNAB, n. 23, p. 58-63, dez. 2019.

FREITAS, S. As Características da Pós-Modernidade como Influencia Estética Contemporânea. Revista Texto Digital, Florianópolis, UFSC, v. 8, n. 2, p. 68-82, jul./dez. 2012.

GIDDENS, A. As Consequências da Modernidade. São Paulo: Editora UNESP, 1991.

LIMA, C. C. O Tratamento do Superendividamento e o Direito de Recomeçar dos Consumidores. São Paulo: Editora Revista dos Tribunais, 2014.

MONTEIRO, V. Quem quer Produtos para Durar? GVExecutivo, São Paulo, EAESP-FGV, v. 18, n. 4, p. 45-47, jul./ago. 2019.

PINTO VIEIRA, A.; KACHUBA, D.; LOCATELLI, L. Sociedade de consumo, superendividamento e economia comportamental. Revista Contribuciones a las Ciencias Sociales, Málaga (Espanha), SAI, mar. 2020.

Disponível em: https://www.eumed.net/rev/cccss/2020/03/sociedade-consumo.html. Acesso em: 17 mar. 2020.

PAGLIUCHI DA SILVEIRA, R. C. Uma contribuição para o Estudo do Ensaio Científico Avaliativo. Revista Letras, Santa Maria, UFSM, n. 2, p. 133-142, jul./dez. 1999.

VEBLEN, T. A Teoria da Classe Ociosa: Um estudo econômico das instituições. São Paulo: Editora Nova Cultural, 1987.

VEBLEN, T. Some Neglected Points in the Theory of Socialism. The Annals of the American Academy of Political and Social Science, Los Angeles (EUA), v. 2, p. 57-74, nov. 1891. Disponível em: http://www.jstor.org/stable/1008995?seq=1\#page_scan_tab_contents. Acesso em: 30 dez. 2019.

STRATHERN, P. Uma breve história da economia. Rio de Janeiro: Zahar, 2003.

WOOLF, V. Street Haunting and other essays. London: Vintage Classics, 2014.

\section{POLÊM!CA $\mid$ LABORE}

Polêmica - Revista Eletrônica da Uerj - Rua São Francisco Xavier, 524, $1^{\circ}$ andar bloco D, sl.1001 • Tels.: +55 21 2334-4088 / 4087 • http://www.e-publicacoes.uerj.br/index.php/polemica/index http://www.labore.uerj.br • laboreuerj@yahoo.com.br 
Recebido em: 26/03/2020.

Aceito em: 30/04/2020.

\section{POLÊM!CA $\mid$ LABORE}

Polêmica - Revista Eletrônica da Uerj - Rua São Francisco Xavier, 524, $1^{\circ}$ andar bloco D, sl.1001 • Tels.: +55 21 2334-4088 / 4087 • http://www.e-publicacoes.uerj.br/index.php/polemica/index http://www.labore.uerj.br・ laboreuerj@yahoo.com.br 